\title{
REFLEKSI PENCIPTAAN MANUSIA BERBANGSA-BANGSA DAN BERSUKU-SUKU (TELAAH SURAH AL-HUJURÂT AYAT 13)
}

\author{
Mirhan AM \\ Jurusan Perbandingan Agama Fakultas Ushuluddin dan Humaniora \\ IAIN Antasari Banjarmasin \\ Diterima tanggal 5 Pebruari 2015/ Disetujui tanggal 19 Meret 2015
}

\begin{abstract}
In the uniqueness and the various of creating of human covered by Allah The almighty, we can take a study about the relationship between the Quran exegesis and the creating of human, then it reveals the differences of quality between one social community and the others according to their group. Islam with Quran argumentation only sees and values of people based on their piety to The God, Allah, not fromthe body shape, colour of skin, superiority of certain nation, the language, culture and custom, and other social regulation.
\end{abstract}

Kata kunci: Penciptaan Manusia, Kekuasaan Allah, al-Qu'ran dan Ketakwaan

\section{Pendahuluan}

Salah satu bukti kekuasaan Allah adalah penciptaan manusia dengan beragam suku, budaya, warna, bahasa, sifat dan lain sebagainya. Hampir dipastikan tidak ada satu manusia yang persis sama dengan manusia lainnya dalam semua hal. Meski semua tampak berbeda namun pada mulanya mereka tercipta dan terlahir dari dua pasangan manusia yang sama yakni Adam dan Hawa. Dari dua nenek moyang manusia ini seterusnya melahirkan perbedaan bangsa dan suku di kalangan umat manusia.

Penciptaan manusia dengan beragam bangsa dan suku tentunya tidak dimaksudkan untuk mengunggulkan satu bangsa atau bangsa lainnya dari segi penciptaan.Perbedaan postur tubuh, warna kulit, bahasa, budaya dan adat istiadat serta pranata sosial lainnya juga tidak dimaksudkan untuk memecah belah umat manusia menjadi kelompok yang saling bermusuhan serta bersikap fanatik terhadap budayanya. Semua yang ada pada manusia berupa fisik dan perangkat budayanya merupakan sesuatu yang taken for granted, dimana seseorang tidak mampu menolaknya. Karena itu, ia tidak menjadi dasar untuk mengukur kemuliaan seseorang. Islam mengajarkan bahwa ketakwaan dan amal saleh yang menjadi barometer kemuliaan.

Kata bangsa dan suku dalam al-Qur'an sering dipahami dengan ungkapan sya'b dan qabîlah. Di samping itu terdapat kata lainnya yakni ‘qawm' dan 'ummah'. Menurut Quraish Shihab, katakata tersebut tidak menunjukkan arti bangsa sebagaimana yang dimaksud pada istilah masa kini. Ia menambahkan, setidaknya ada enam unsur yang membentuk suatu bangsa yakni: keturunan, asal keturunan, bahasa, adat istiadat dan cinta tanah air. ${ }^{1}$

${ }^{1}$ M. Quraish Shihab, Wawasan Al-Qur'an; Tafsir Maudhu'i atas Pelbagai Persoalan Umat, Cet. III, (Bandung: Mizan, 1996), h. 334-345. 
Lantas bagaimana memahami makna Surah al-Hujurât ayat 13 yang berbicara tentang asal usul keturunan manusia termasuk diantaranya pemahaman kata sya'b dan qabîlah? Tulisan ini berusaha memahami tersebut dengan menggunakan bahasa penafsiran.

\section{Sekilas Tentang Tahlîli}

Menurut al-Farmâwî sebagaimana yang dikutip oleh Ahmad Syukri, bahwa metode analisis atau tahlîli adalah suatu metode tafsir yang bermaksud menjelaskan kandungan ayat-ayat alQur'an dari seluruh aspeknya. Sistematika metode analisis biasanya diawali dengan mengemukakan korelasi (munâsabah), baik antar ayat maupun surat. Lalu menjelaskan latar belakang turunnya ayat (asbâb al-nuzûh), menganalisis kosa kata dan lafaz dalam konteks bahasa Arab, menyajikan kandungan ayat secara global, menjelaskan hukum yang dapat dipetik dari ayat dan terakhir menerangkan makna dan tujuan syara' yang terkandung dalam ayat. Khusus untuk corak tafsir ilmu pengetahuan ('ilmî) dan sastra sosial kemasyarakatan (al-adabi al-ijtimầ), biasanya penafsir memperkuat argumentasinya dengan mengutip langsung ke al-Farmâwî.

Menurut Ahmad Syukri, metode tablîli lahir setelah metode global (ijmâli) sudah tidak mampu memenuhi hasrat umat Islam untuk mengetahui kandungan ayat al-Qur'an. Dengan tersebarnya Islam ke berbagai kawasan yang berpenduduk non Arab, penjelasan secara rinci akan kandungan al-Qur'an dari berbagai aspeknya sangat diperlukan, Kondisi inilah yang kemudian melahirkan tafsir tahlili. Dalam prakteknya, menurut Ahmad Syukri, metode ini mencakup dua bentuk tafsir klasik yakni ma'tsur dan ra 'y. ${ }^{2}$

Dalam kajian tafsir dan ulumul qur'an, para ulama membagi jenis tafsir menjadi dua yakni tafsir bi al-ma'tsûr dan tafsir bi al-ra'y. Tafsir bi al-ma'tsûr adalah tafsir yang didasarkan pada riwayat yang benar baik penafsiran al-Qur'an dengan al-Qur'an, sunnah, atau berdasarkan riwayat para sahabat, atau riwayat para pemuka tabi'in yang menerima penafsirannya dari para sahabat. ${ }^{3}$ Sedang tafsir bi al-ra'y adalah tafsir yang menyandarkan penafsiran ayatnya hanya pada akal semata.Tafsir jenis ini yang diharamkan oleh ulama. ${ }^{4}$

\section{Pembahasan}

Mengenai penjelasan manusia dengan beragam bangsa dan suku dengan tujuan untuk saling mengenal dan berhubungan secara baik satu sama lain, al-Qur'an menegaskan :

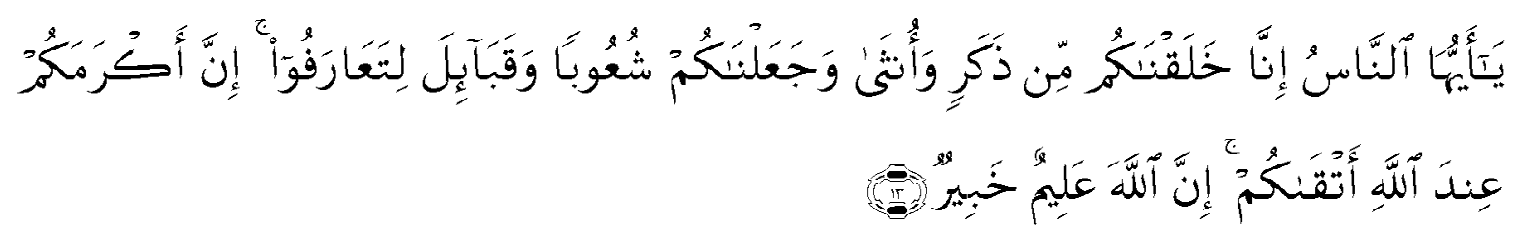

Artinya: "Hai manusia, Sesungguhnya kami menciptakan kamu dari seorang laki-laki dan seorang perempuan dan menjadikan kamu berbangsa - bangsa dan bersuku-suku supaya kamu saling kenalmengenal. Sesunggubnya orang yang paling mulia diantara kamu disisi Allah ialah orang yang paling

${ }^{2}$ Ahmad Syukri Saleh, Metodologi Tafsir al-Qur 'an Kontemporer dalam Pandangan Fazlur Rahman, Cet; II, (Jakarta: Gaung Persada Press, 2007), h. 47-48.

${ }^{3}$ Mannâ' al-Qattân, Mabâhits fî̀ 'Ulûm al-Qur'ân,(Kairo: Maktabah Wahbah, 1997), h. 337.

${ }^{4}$ Mannâ' al-Qattân, Mabâbits fì 'Ulûm al-Qur'ân, h. 342. 
taqwa diantara kamu. Sesunggubnya Allab Maha mengetahui lagi Maha Mengenal.” (QS. Al49:13)

Kata syu'ûb merupakan bentuk jamak dari kata sya'b. Kata sya'b sendiri memiliki dua makna yang saling bertentangan yakni berpisah dan bersatu. Ahli bahasa juga berbeda pendapat mengenai makna kata tersebut. Ada yang mengatakan maknanya qawm atau kaum. ${ }^{5}$ Sedang qabîlab berasal dari kata qabila yang berarti sesuatu yang berhadapan dengan sesuatu yang lain dan kemudian berpisah. ${ }^{6}$ Sedang al-Qurthubi memahami kata sya'b dengan para pemuka kabilah seperti Rabî’ah, Mudhâr, Aus dan Khajraz. Dinamakan demikian, karena mereka bersatu. ${ }^{7} \mathrm{Al}-$ Jawhari mengatakan makna sya'b adalah bersatunya beberapa kabilah Arab dan non Arab. Sedang Ibn Ábbâs mengatakan bahwa syu'ûb adalah kelompok besar seperti Bani Mudhâr. Sedang kabilah adalah kelompok kecil. Sementara itu, Mujahid mengatakan bahwa syu'ûb berarti keturunan dari jalur nasab yang jauh sedang qabaîl adalah jalur nasab yang dekat. ${ }^{8}$ Masih banyak lagi pemaknaan Kata syu'ûb yang diuraikan al-Qurtubi dalam tafsirnya namun apa yang disebutkan di atas mungkin cukup untuk memahami maksud kata tersebut.

Dalam Tafsir Jalâlayn, dinyatakan bahwa sya'b bermakna urutan tingkat nasab yang tertinggi sedang di bawahnya adalah kabilah dan berikutnya secara berturut-turut al-'amâir, al-buthîn, alafkhâa, kemudian al-fasâil. ${ }^{9}$ Dengan pengertian ini, menurut Quraish, kata sya'b tidak dapat dipahami dengan pengertian bangsa sebagaimana yang dimaksud dewasa ini. ${ }^{10}$

Setidaknya ada dua sebab turunnya ayat ini yang sering dikutip para mufasir berdasarkan jalur periwayatan. Riwayat Pertama, mengatakan bahwa sebab turunnya ayat ini berkenaan dengan Bilal. Pada saat Fath Makkah Bilâl naik ke atas Ka'bah kemudian mengumandangkan azan. Sebagian orang berkata: 'Apakah hamba hitam ini yang azan di depan Ka'bah? Sebagian lain mengatakan: 'Jika Allah murka atau menolak akan hal ini niscaya la akan merubahnya. Kemudian turunlah ayat ini dan Nabi memanggil mereka seraya mengingatkan untuk tidak membanggakan keturunan, harta dan hendaklah perhatian pada kaum fakir miskin. Peristiwa ini diriwayatkan oleh Abû Hâtim dari ibn Abî Mulaikah.

Riwayat kedua, yang berasal dari Abû Bakar bin Abû Dâwûd dalam tafsirnya mengatakan bahwa ayat ini berkenaan dengan Abû Hind di mana Rasulullah memerintahkan kepada Bani Bayadah agar menikahkan salah seorang anak perempuan mereka dengan Abu Hind. Mereka kemudian mengatakan: "Apakah kami akan menikahkan anak perempuan kami dengan bekas budak kami?" Lalu turunlah ayat ini. ${ }^{11}$

\footnotetext{
${ }^{5}$ Abu al-Husain Ahmad bin Faris bin Zakariyya, Mu'jam al-Maqâyîs fi al-Lugah, (Beirut: Dar al-Fikr, 1994), h. 527.

${ }^{6}$ Abu al-Husain Ahmad bin Faris bin Zakariyya, Mu'jam al-Maqâŷis fi al-Lugah, h. 872.

${ }^{7}$ Muhammad ibn Ahmad ibn Abî Bakr ibn Farh al-Ansârî al-Qurtubi, al-Jâmi' li A Ahkâm al-Qur 'ân, Juz. XVI, (Riyâdh: Dâr 'Alam al-Kutub, 2003), h. 343.

${ }^{8}$ Muhammad ibn Ahmad ibn Abî Bakr ibn Farh al-Ansârî al-Qurthubi, al-Jâmi’ li Ahkâm al-Qur 'ân, h. 343.

${ }^{9}$ Jalâluddin Muhammad ibn Ahmad ibn Muhammad al-Mahalli dan Jalâluddin Abdurrahmân ibn Abî Bakr alSuyûtî,al-Qur'ân al-Karîm wa bi Hâmisyah Tafsîr al-lmâm al-Jalâlain, (t.p.: Dar Ibn Kasir, t.th.), h. 517.

${ }^{10}$ M. Quraish Shihab, Tafsir al-Misbah: Pesan, Kesan dan Keserasian al-Qur'an, vol. 13, Cet. IV, (Jakarta: Lentera Hati, 2006), h. 262.

${ }^{11}$ Wahbah al-Zuhaily, al-Tafsîr al-Munîrfi al-'Aqîdah wa al-Syaríah wa al-Manhaj, Juz XXVI, (Beirut: Dâr al-Mu'âtsir, 1991), h. 250.
} 
Pada ayat sebelumnya, dijelaskan mengenai apa yang harus dilakukan oleh seorang muslim terhadap Allah, Nabi dan terhadap orang yang menantang serta menyalahi keduanya yakni kaum fasik. Namun pada ayat ini Allah menjelaskan tentang sikap yang harus dimiliki seorang muslim terhadap mukmin lainnya dan manusia pada umumnya dengan tidak mencela, mencaci, ghibah, mengadu domba dan mengharuskan mereka memperlakukan orang lain dengan setara (musâwâh) dengan landasan bahwa kemuliaan seseorang terletak pada takwa, kebaikan dan akhlak yang sempurna. ${ }^{12}$

Ketika menafsirkan ayat ini, al-Qurthubi menyatakan ada empat persoalan yang dimuat dalam kandungan ayat tersebut. Pertama, pada kalimat "yâa ayyuha al-nâs innâ khlaqnâkum min dzakar wa untsâ" menunjukkan makna Adam dan Hawa. Dengan ungkapan lain ayat tersebut ditafsirkan oleh Quraish dengan makna sperma (benih laki-laki) dan ovum (indung telur perempuan).${ }^{13}$ Kedua, dengan ayat itu Allah menjelaskan bahwa Dia menciptakan manusia dari pasangan laki-laki dan perempuan. Sekiranya Dia menghendaki, niscaya la mampu menciptakan manusia tanpa berasal dari keduanya seperti Adam, atau tanpa laki-laki seperti penciptaan Ísa, atau tanpa perempuan seperti penciptaan Hawa. Ketiga, dari laki-laki dan perempuan, Allah menciptakan manusia dengan beragam nasab, kabilah dan suku agar mereka saling mengenal. Keempat, bahwa manusia diciptakan dari air mani laki-laki dan perempuan. Ayat ini membantah pandangan terdahulu yang mengatakan bahwa janin hanya tercipta dari air mani laki-laki kemudian tersimpan dalam rahim ibu dan menjadi darah. Mereka mendasarkan pandangan ini, salah satunya dari pemahaman akan surah al-Mursalât ayat 20 dan 21 yang berbunyi: ${ }^{14}$

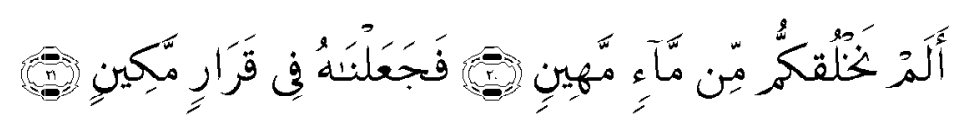

Artinya :"Bukankah kami menciptakan kamu dari air yang bina? Kemudian kami letakkan dia dalam tempat yang kokoh (rahim).” (QS. al-Mursalât: 20-21)

Kalimat "inna akramakum inda Allah atqâkum" dijelaskan dalam hadits Nabi saw. yang berbunyi :

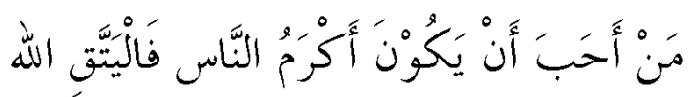

Artinya :"Siapa yang ingin menjad manusia paling mulia maka bertakwalah pada Allab"

Takwa di sini ditafsirkan dengan memelihara diri dari aturan Allah baik perintah maupun larangan-Nya. ${ }^{15}$ Quraish berpendapat bahwa ayat ini berbicara tentang prinsip dasar hubungan antar manusia. Karena itu, menurutnya, ayat tersebut tidak menggunakan panggilan yang ditujukan kepada orang-orang beriman, tetapi kepada jenis manusia.

Atas dasar asbâb al-nuzûl tersebut, menurut Quraish, ayat di atas secara jelas menegaskan kesatuan asal usul manusia dengan menunjukkan kesamaan derajat kemanusiaan manusia. Sehingga tidak wajar seseorang berbangga dan merasa diri lebih tinggi dari yang lain, bukan

\footnotetext{
${ }^{12}$ Wahbah al-Zuhaily, al-Tafsîr al-Munîr fi al-'Aqîdah wa al-Syarìah wa al-Manhaj, Juz XXVI, h. 250.

${ }^{13}$ M. Quraish Shihab, Tafsir al-Misbah: Pesan, Kesan dan Keserasian al-Qur'an, vol. 13, Cet. IV, h. 260.

${ }^{14}$ Muhammad ibn Ahmad ibn Abî Bakr ibn Farh al-Ansârî al-Qurthubi, al-Jâmi’ li Ahkâm al-Qur 'ân, h. 340.

${ }^{15}$ Muhammad ibn Ahmad ibn Abî Bakr ibn Farh al-Ansârî al-Qurthubi, al-Jâmi’ li Ahkâm al-Qur 'ân,h. 345.
} 
saja antar satu bangsa, suku, atau warna kulit dengan selainnya, tetapi antara jenis kelamin mereka.

Dalam konteks ini, sewaktu haji wada' (perpisahan), Nabi saw. berpesan antara lain: 'Wahai seluruh manusia, sesungguhnya Tuhan kamu Esa, ayah kamu satu, tiada kelebihan orang Arab atas non Arab, tidak juga non Arab atas orang Arab, atau orang (berkulit) hitam atas yang (berkulit) merah (yakni putih) tidak juga sebaliknya kecuali dengan takwa, sesungguhnya semuliamulia kamu di sisi Allah adalah yang paling bertakwa." (H.R. al-Baihaqi melalui Jabir ibn Abdillah)

"Ta'ârafu” terambil dari kata 'arafa yang berarti mengenal. Patron kata yang digunakan ayat ini mengandung makna timbal balik, dengan demikian ia berarti saling mengenal. ${ }^{16}$ Menurut alZamakhsyari, makna li ta'arafu adalah agar kalian mengetahui nasab-nasab dan bukan dimaksudkan untuk membanggakan dan mengagungkan asal usul keturunan serta merendahkan keturunan lainnya karena ayat tersebut diakhiri dengan pernyataan bahwa orang yang mulia adalah yang paling bertakwa. ${ }^{17} \mathrm{Hal}$ ini senada dengan pandangan Mujahid yang memahami makna tersebut dengan mengatakan bahwa si fulan berasal dari keturunan A dan B (keturunan tertentu). ${ }^{18}$

Kata "akramakum"terambil dari kata karuma yang pada dasarnya berarti yang baik dan istimewa sesuai objeknya. Manusia yang baik dan istimewa adalah yang memiliki akhlak yang baik terhadap Allah, dan terhadap sesama makhluk. Kemulian abadi hanya ada di sisi Allah dan untuk mencapainya adalah dengan mendekatkan diri kepada-Nya, menjauhi larangannya, melaksanakan perintahnya serta meneladani sifat-sifat-Nya sesuai kemampuan manusia. Hal itulah yang disebut dengan takwa. ${ }^{19}$

Salah satu makna dari penggabungan kata 'alîm dan khabîr adalah bahwa kualitas ketakwaan dan kemuliaan seseorang di sisi Allah merupakan sesuatu yang sangat sulit, bahkan mustahil bagi seorang manusia dapat menilai kadar dan kualitas keimanan serta ketakwaan seseorang, yang mengetahui hanya Allah swt. ${ }^{20}$

Ada beberapa bentuk pembelajaran yang disampaikan Allah kepada umat Islam melalui ayat ini, yakni:

Pertama, ajaran kesetaraan (al-musâwâh) diantara manusia dalam hal asal kelahiran dan kemuliaan dengan takwa.

QS. al- Hujurât ayat 13, Allah menyatakan bahwasemua manusia terlahir dari asal dan jiwa yang satu yakni Adam dan Hawa. Semua manusia sama karena terlahir dari satu nasab, satu ibu dan bapak, sehingga tidak pantas untuk berbangga dengan nasab dan tidak boleh pula menghina dan mencela. Allah menciptakan Manusia berbangsa-bangsa (satu umat besar yang terdiri dari beberapa kabilah) agar saling mengenal. Sedang orang yang paling mulia adalah orang yang bertakwa. Ayat ini dijadikan dalil oleh pengikut Maliki untuk tidak mensyaratkan kafâ'ah dalam pernikahan kecuali atas dasar agama. ${ }^{21}$

${ }^{16}$ M. Quraish Shihab, Tafsir al-Misbab: Pesan, Kesan dan Keserasian al-Qur'an, vol. 13, Cet. IV, h. 262.

${ }^{17}$ Abû al-Qâsim Mahmûd ibn 'Umar al-Zamakhsyari, al-Kasysyâf 'an Haqâ’iq al-Tanz̧îl wa 'Uyûni al-Aqâwñl fi Wujûhi alTa'wîl, Vol.4, (Beirut: Dâr Ihya al-Turats al-'Arabi, t.th), h. 378.

${ }^{18}$ Abû al-Fidâ Ismâ'il bin 'Umar bin Katsîr al-Qurasyi, Tafsîr al-Qur'ân al-'Az̧hìm, Vol.7, (Riyâdh: Dâr Thayyibah li alNasyr wa al-Tawzi’, 1999), h. 385.

${ }^{19}$ M. Quraish Shihab, Tafsir al-Misbah: Pesan, Kesan dan Keserasian al-Qur'an, Vol. 13, h. 263.

${ }^{20}$ M. Quraish Shihab, Tafsir al-Misbah: Pesan, Kesan dan Keserasian al-Qur'an, Vol. 13, h. 263.

${ }^{21}$ Al-Zuhaily, at-Tafsîr al-Munîr, h. 260. 
Terdapat banyak hadis yang menyatakan kesamaan manusia di antaranya hadis yang diriwayatkan al-Bazzar dalam musnadnya dari Huzifah dari Nabi saw. bersabda:

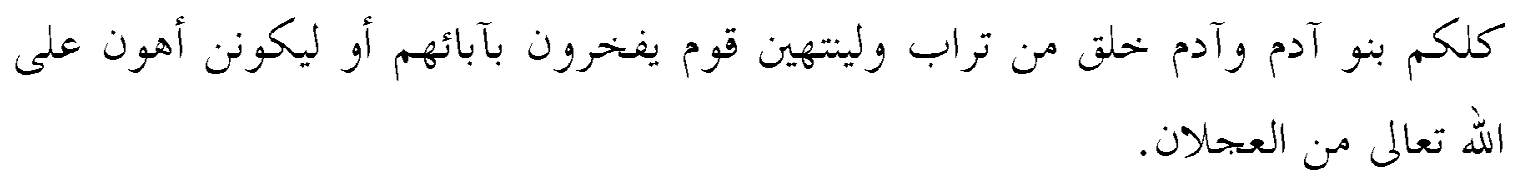

Artinya :"Setiap kalian adalah keturunan Adam, sedang Adam diciptakan dari tanah. Hendaklah suatu kaum untuk tidak berbangga akan keturunannya atau ia akan dipandang bina dihadapan Allah dibanding budak."

Kedua, ayat ini memuat ajaran kesetaraan antar manusia, anjuran untuk saling mengenal sesama manusia dan kemuliaan hanya didapat dengan takwa dan amal saleh. ${ }^{22}$

\section{Penutup}

Berdasarkan uraian tersebut di atas maka dapat disimpulkan bahwa ayat tersebut berbicara tentang asal penciptaan manusia dari nenek moyang yang sama, yakni Adam dan Hawa atau dari sperma laki-laki dan ovum perempuan. Meski manusia diciptakan dengan beragam bangsa dan suku, namun ulama sepakat bahwa perbedaan tersebut tidak dimaksudkan untuk menunjukkan kelebihan satu bangsa atas bangsa lainnya. Dengan ungkapan lain, bahwa kemuliaan suatu kaum atau seseorang tidak ditentukan dari keturunan dan kebangsaannya atau nenek moyangnya, tapi karena kualitas pribadi orang itu sendiri. Dalam pandangan Islam, semua manusia dipandang sama dan kualitas seseorang ditentukan dengan takwa dan amal shalehnya. Dengan ini, Islam mengajarkan paham kesetaraan di antara seluruh manusia. Dari sisi teologis, adanya perbedaan masing-masing orang menunjukkan keberadaan dan kekuasaan Allah untuk menciptakan manusia dengan segala keunikan dan keragamannya, meski pada asalnya bersumber dari nenek moyang yang satu.

\section{DAFTAR PUSTAKA}

Al-Mahalli, Jalaluddin Muhammad ibn Ahmad ibn Muhammad, Jalâluddin Abd al-Rahmân ibn Abû Bakr al-Suyûtî. (t.th.) al-Qur'ân al-Karîm wa bi Hâmisyah Tafsîr al-lmâm al-Jalâlaiyn, t.p.: Dar Ibn Kasir.

Al-Qathân, Mannâ’. (1997). Mabâbits fî 'Ulûm al-Qur'ân, Kairo: Maktabah Wahbah.

Al-Qurthubi, Muhammad ibn Ahmad ibn Abû Bakr ibn Farh al-Ansârî. (2003). al-Jâmi' li Abkâm al-Qur 'ân, Riyâdh: Dâr 'Âlam al-Kutub.

Al-Zamakhsyari, Abû al-Qâsim Mahmûd ibn 'Umar. (t.th). al-Kasysyâf 'an Haqẩiq al-Tanzîl wa 'Uyûn al-Aqânîl fi Wujûhi al-Ta'wîl, Beirut: Dâr Ihya al-Turats al-'Arabi.

Al-Zuhaily Wahbah. (1991). at-Tafsîr al-Munîr fi al-'Aqîdah wa al-Syarîah wa al-Manhaj, Beirut: Dâr al-Mu'âshir.

\footnotetext{
${ }^{22}$ Al-Zuhaily, at-Tafsîr al-Munîr, h. 265.
} 
Ibn Katsîr al-Qurasyi, Abû al-Fidâ Ismâ'il bin 'Umar. (1999). Tafsîr al-Qur'ân al-'Az̧hîm, Riyâdh: Dâr Thayyibah li al-Nasyr wa al-Tawzi'.

Ibn Faris bin Zakariyya Abu al-Husaiyn Ahmad. (1994). Mu'jam al-Maqâyîs fi al-Lughah, (Beirut: Dar al-Fikr.

Saleh , Ahmad Syukri. (2007). Metodologi Tafsir al-Qur 'an Kontemporer dalam Pandangan Fazlur Rahman, Jakarta: Gaung Persada Press.

Shihab, M. Quraish. (1996). Wawasan Al-Qur'an; Tafsir Maudbu'i atas Pelbagai Persoalan Umat, Bandung: Mizan. . (2006). Tafsir al-Misbah: Pesan, Kesan dan Keserasian al-Qur'an, Jakarta: Lentera Hati. 